\title{
Delirium and Associated Factors Among Older Patients in Coronary and Internal Medicine Intensive Care Units of a University Hospital
}

\author{
(D) Zeynep Dilek Aydın1, (1D Hatice Yıldırım² \\ 'Süleyman Demirel University Faculty of Medicine, Department of Internal Medicine, Division of Geriatrics, Isparta, Turkey \\ ${ }^{2}$ Isparta Şehit Yunus Emre State Hospital, Clinic of Internal Medicine, Isparta, Turkey
}

\begin{abstract}
Objective: Delirium in intensive care units (ICUs) is associated with increased mortality, cognitive decline, prolonged hospitalization and increased likelihood of discharge to nursing home. Therefore, we aimed to evaluate its prevalence and the associated risk factors in two ICUs.

Materials and Methods: In this cohort study, delirium frequency was evaluated among 100 patients aged 65 and over in the internal medicine and coronary ICUs of Süleyman Demirel University Faculty of Medicine using the confusion assessment method and daily evaluations during May-June 2015. Cognitive and functional evaluations were performed and socio-demographic and clinical characteristics were recorded.

Results: Overall, delirium prevalence was $15 \%$ and it was more common in the internal medicine ICU compared to coronary ICU (52\% vs $2.7 \%)$. In univariate analysis, age and Charlson comorbidity index and eight-item "Informant Interview to Differentiate Aging and Dementia" (AD8) scores were higher and Barthel activities of daily living index, Lawton-Brody instrumental activities of daily living scale and mini-mental state examination scores were lower in delirious patients. In multivariate logistic regression analysis, Barthel index was the only independent predictor of delirium. Barthel, Lawton-Brody, mini-mental state examination and AD8 scores were different among patients in the internal medicine ICU and those in coronary ICU.
\end{abstract}

Conclusion: Delirium and its risk factors were observed more frequently among internal medicine ICU patients. Moreover, activities of daily living score was the strongest predictor of delirium risk.

Keywords: Delirium, medical intensive care unit, coronary intensive care unit, activities of daily living, cognition

\section{Introduction}

Delirium is an acute confusional state characterized by reduced ability to focus, sustain, or shift attention (1). According to the fifth edition of the "Diagnostic and Statistical Manual of the American Psychiatric Association" (DSM-V) (2), it is characterized by a disturbance in attention and awareness, disturbance that develops over a short period of time (usually hours to a few days), an additional disturbance in cognition, evidence from the history, physical examination or laboratory findings that the disturbance is a direct physiological consequence of another medical condition, substance intoxication or withdrawal or a medication side effect. Therefore, the diagnosis is established clinically with medical history and examination.

However, making delirium diagnosis in intensive care units (ICUs) using these criteria is time consuming and requires comprehensive education. "Confusion Assessment Method" (CAM) is a structured tool developed by Inouye et al. (3) in 1990 that enables to evaluate delirium symptoms stated in DSM-III-R. CAM has been determined to be the best test in terms of accuracy in a research comparing 11 bedside instruments to detect delirium presence (4). According to the meta-analysis by Wei et al. (5), sensitivity and specificity of CAM were $94 \%$ and $89 \%$, respectively.

Address for Correspondence: Zeynep Dilek Aydın, Süleyman Demirel University Faculty of Medicine, Department of Internal Medicine, Division of Geriatrics, Isparta, Turkey

Phone: +90 2462119222 E-mail: zdilekaydin@gmail.com ORCID: orcid.org/0000-0002-4462-8970

Received: Oct 06, 2019 Accepted: Oct 28, 2019

Cite this article as: Aydın ZD, Yıldırım H. Delirium and Associated Factors Among Older Patients in Coronary and Internal Medicine Intensive Care Units of a University Hospital. Eur J Geriatr Gerontol 2019;1(3):87-93

๑Copyright 2019 by the Academic Geriatrics Society / European Journal of Geriatrics and Gerontology published by Galenos Publishing House. 
Delirium occurs in $14 \%$ to $56 \%$ of elderly patients during hospitalization (6) and its prevalence is even higher in the ICU (7). In ICU, delirium is associated with increased mortality, increased cognitive decline, prolonged hospitalization and an increase in the likelihood of discharge to a nursing home (8). It is known that a day with delirium increases the hospitalization duration by $20 \%$ and mortality by $10 \%$ (9). Therefore, delirium diagnosis and treatment are very important in ICUs.

Predisposing and precipitant risk factors are in interaction in delirium development. Predisposing risk factors for delirium are the characteristics that the patient has at admission (10). Predisposing risk factors involve age (especially above 70 years), dementia, living in a nursing home, cigarette and alcohol use, illegal medication use, visual and hearing disorders, high urea-creatinine levels, history of stroke, epilepsy, congestive heart failure and depression. Precipitating factors arise as a consequence of noxious insults or hospitalrelated issues. Precipitant factors are infection, sepsis, hypoxia, metabolic disorders, electrolyte imbalance, malnutrition, hypohyperglycemia, hypo-hyperthyroidism, hypo-hypernatremia, dehydration, hemodynamic instability, cerebral and vascular disorders (such as hypertension), head trauma and seizures. In addition, some pharmacological agents are among the precipitant factors as well. Adding three or more medications to the treatment or abrupt withdrawal of continuously used medications in ICU patients may be triggering factors for delirium as well (11).

The importance of this subject is explicit as delirium is a clinical condition affecting important end points such as mortality and functional condition. Recognizing delirium and using appropriate approaches may affect the prognosis positively. In this study, we aimed to detect the delirium prevalence in patients aged 65 years and older hospitalized in coronary ICU (CICU) and medical ICU (MICU) using CAM and to analyze the associated factors.

\section{Materials and Methods}

All patients aged 65 and older hospitalized in Süleyman Demirel University MICU ( $n=25)$ and CICU $(n=75)$ between May 2015 and June 2015 were included in this cohort study. The study was approved by Süleyman Demirel University Faculty of Medicine Ethics Committee, and informed consent was obtained from the patients or their relatives (decision no: 202)

Data were collected with a questionnaire. All assessments were made by a single investigator who is an internist (HY). Data were collected directly from the patients $(n=65)$ or from the relatives when the patient was unable to provide information $(n=35)$. AD8 dementia screening was performed by interviewing the relatives/caregivers of the patients.
All assessments except CAM were performed only once at the time of initial admission to the ICU whereas CAM was performed daily. The one-time assessments included socio-demographic characteristics, clinical information, Charlson comorbidity index $(\mathrm{CCl})$, Barthel activities of daily living (ADL) Index, LawtonBrody instrumental ADL (IADL) scale and Mini-mental State Examination (MMSE); these assessments reflected the current condition of the patient.

The presence of delirium was assessed with CAM which evaluates delirium symptoms (3). Delirium is diagnosed when both acute onset/fluctuating course and inattention are present (features 1 and 2) and at least one of other two features (disorganized thinking or altered level of consciousness). Validity and reliability studies of the ICU form of this tool (CAM-ICU) have been performed by Akinci et al. (12) in 2005. Patients were evaluated daily (including the weekends) with CAM by one of the investigators (HY). If the patient meets the delirium criteria with CAM in at least one day, the patient was considered to have delirium.

The $\mathrm{CCl}$ consists of 19 selected conditions that are weighted and summed to an index on a 0-33 scale. $\mathrm{CCl}$ estimates mortality based on combined age-comorbidity score (13). Increased score is associated with increased mortality. The $\mathrm{CCl}$ is the most extensively studied comorbidity index and its validity has been studied in diverse patient groups (14). CCl also appears to be a valid instrument in predicting mortality and length of stay in critically ill elderly Turkish patients (15).

Barthel ADL index consists of 10 items of daily life activities and mobility. Nutrition, ability to transfer from wheelchair to bed and turn in bed, self-care, bath, walk, climb and descend a ladder, dress, and bladder and bowel continence are examined. A score is calculated according to whether the patient receives help during these activities or not. The highest score is 100 and it means that the individual is completely independent in physical activities. The lowest score is 0 and it means that the individual is completely dependent (16). The validity and reliability of the Turkish version of the Barthel ADL index was assesed by Küçükdeveci et al. (17) in patients with stroke and spinal cord injury.

Lawton-Brody IADL index examines eight instrumental daily life activities; using the phone, shopping, preparing food, laundering, house cleaning, using transportation, taking the responsibility for own medications and handling finances. A modified scoring of the Lawton-Brody IADL index was used by giving points between 0 and 3 to each activity with a total score of 24 points instead of assigning a score of 0 or 1 for each activity with a total score of 8 points in the original version (18). Individuals who perform activities independently take 3 points, those who get help during the activities take 1 or 2 points and those who cannot participate in the activity at all take 0 points. A greater score indicates greater ability to perform IADL. 
AD8 dementia screening interview is an informant based short and sensitive measure which consists of eight items and discriminates the individuals with and without dementia in a valid and reliable manner. It shows equal reliability in both face to face and phone interviews (19). The informant (such as a spouse or caregiver) is asked to rate the patient according to eight questions pertaining to cognitive function (the AD8). Turkish validation-reliability study of AD8 had not been performed as of May 2015, when our study was conducted. We used a modified version of Dr. Cenk Akbostanci's translation of the questionnaire by courtesy of the authors. Recently Usarel et al. (20) published the validity and reliability assessment of AD8. Unfortunately, our study utilized an unvalidated translation. Nevertheless, a score of $\geq 2$ is considered as a further evaluation criterion in terms of dementia (19). In our study, both total AD8 score and AD8 score of $\geq 2$ have been examined in terms of their relation with delirium.

MMSE is the most commonly used cognitive test in clinical practice in USA (21). MMSE tests various cognitive functions such as orientation, memory, attention, calculation, language and visuospatial abilities. Maximum score in MMSE is 30. A score under 24 indicates an impairment in cognitive function. There are two versions of the MMSE test for educated and illiterate patients. The validation and reliability of MMSE test in mild dementia diagnosis in a Turkish population who attended school for at least five years was performed by Güngen et al. (22) in 2002. The validation and reliability study of MMSE for the illiterate was performed by Babacan-Yıldız et al. (23) in 2015.

\section{Statistics}

Data was analyzed using SAS 9.4, $p<0.05$ was considered significant. In descriptive analyses, mean and standard deviations are presented for continuous variables with normal distribution, median (range) for continuous variables with nonnormal distribution and number $(\mathrm{n})$ and percentages $(\%)$ for the categorical variables. Characteristics were compared between the patients hospitalized in MICU and $\mathrm{CICU}$ and between the patients who developed and did not develop delirium.

In group comparisons (MICU vs $\mathrm{CICU}$ and the patients who developed delirium vs the ones who did not), "independent samples t-test" was performed for the continuous variables with normal distribution and "Mann-Whitney $\mathrm{U}$ test" for the continuous variables with non-normal distribution. Chi-square test was performed to compare the categorical data and proportions; Fisher exact test was performed when the lowest expected value in any cell of 2x2 crosstabs was below 5 .

Multivariate logistic regression analysis was performed to determine the factors predicting the likelihood of experiencing delirium independently. All factors listed in tables 1-2 were taken into consideration when the multivariate model was established. A stepwise model selection algorithm was used with two obligatory variables (age and ICU) selected a priori and forced into the model. The stepwise approach was preferred because of the small sample size and large number of variables. The significance level for entering and staying in the model was 0.05 .

\section{Results}

Delirium prevalence was 15\% in all patients in our research group, 52\% in MICU and 2.7\% in CICU using CAM.

Comparison of patient characteristics hospitalized in MICU $(n=25)$ and $\mathrm{CICU}(n=75)$ are shown in Table 1 . In one-by-one comparisons, MICU patients had higher $\mathrm{CCl}$ score and higher AD8 total score at admission and lower Barthel ADL score, lower Lawton-Brody IADL score and lower MMSE score at admission compared to those of $\mathrm{CICU}$ patients.

Comparison of patient characteristics for those who developed delirium $(n=15)$ and who had not $(n=85)$ are shown in Table 2 . In one-by-one comparisons, the patients who developed delirium had higher age, higher CCI score and higher AD8 total score at admission and lower Barthel ADL score, lower Lawton-Brody IADL score and lower MMSE score at admission compared to the ones without delirium.

The multivariate logistic regression analysis is shown in Table 3 with the respective odds ratio, 95\% confidence interval, and $p$ values. Among the examined factors, only Barthel $A D L$ index could predict delirium development independently. Increased Barthel score (i.e. better functional status) is associated with lower delirium risk (Odds ratio $<1$ ).

\section{Discussion}

When CAM was used to determine the delirium prevalence, a significantly higher prevalence was detected in MICU (52\%) compared to CICU (2.7\%). In our study, the delirium prevalence detected in MICU was close to the rates reported in the literature. For instance; Limpawattana et al. (24) detected delirium in $44.4 \%$ of 99 patients aged $>65$ who were hospitalized in a Medical Faculty ICU in Thailand. We could not find any study comparing delirium prevalence in coronary and internal medicine ICUs in the literature. When different studies are evaluated, delirium prevalence seems to be lower than that of MICU in CICU studies, in parallel with our study $(24,25)$. In addition, all CICU delirium rates we could find (16\%-48\%) seem higher than the rates observed in CICU in our study (2.7\%) (25-27).

The reasons for the lower prevalence of delirium in our $\mathrm{CICU}$ is unclear at this point as we have not collected data on specific patient subpopulations or predisposing medical interventions. For instance, specific patient groups such as 
patients with advanced heart failure, patients on mechanical ventricular support devices, patients treated by transcatheter aortic valve replacement and survivors of cardiac arrest present with increased complexity and are at increased risk of delirium in CICU (28). It is also possible that there may be a lower prevalence of interventions that predispose to delirium such as use of indwelling catheters in CICU. These factors remain to be explored in future studies. Nevertheless, it is observed that frequency of many characteristics known to be risk factors for delirium are different in MICU and CICU. CCI, Barthel ADL, Lawton-Brody IADL, MMSE and AD8 scores at admission are the most remarkable ones among these differences.

Number one cause of admission was coronary artery disease in CICU patients (82.7\%) whereas number one cause of admission in MICU was sepsis and infection (28\%) (Table 2). Studies on the causes of admission to MICU report also respiratory problems as a major cause. A MICU study has reported that $47.7 \%$ of 44 patients who developed delirium had pneumonia and other respiratory problems, $18.8 \%$ had sepsis, $11.3 \%$ had heart diseases (24). Similarly, sepsis was the most frequent cause of admission to our MICU, however, respiratory problems were less frequent and this is due to the lack of ventilation support in our MICU.
The most important and the only independent predictor for delirium in our study is the Barthel $\mathrm{ADL}$ score. When age, $\mathrm{CCl}$, Lawton-Brody IADL score, MMSE score and AD8 total score at admission were examined individually, they were found to be associated with delirium presence, however, these factors were not significant in multivariate analysis. Our small sample size can explain the inability to detect some important relationships. Also, in hospitalized elderly Turkish patients, Barthel ADL score as well as IADL and MMSE scores were detected to be low in patients with delirium consistent with findings of our study (29).

In our study, mean age of patients with delirium was higher than that of patients without delirium. This result is consistent with the literature $(24,25,29)$.

In our study group, $\mathrm{CCl}$ score of patients who developed delirium was higher compared to the ones without delirium and $\mathrm{CCl}$ score of patients in MICU was found to be higher than that of the patients in CICU. In other words, there are more patients with comorbid conditions in MICU and among those who had delirium. In the literature, $\mathrm{CCl}$ score of patients who developed delirium is higher than that of patients without delirium in keeping with our findings (30). This demonstrates that individuals with more concomitant comorbid diseases have more tendency to develop delirium.

\begin{tabular}{|c|c|c|c|c|c|}
\hline \multicolumn{2}{|l|}{ Variable } & Total $n=100$ & MICU $n=25$ & CICU $n=75$ & $p$ value \\
\hline \multirow[t]{2}{*}{ Delirium } & Yes, n (\%) & $15(15 \%)$ & $13(52 \%)$ & $2(2.7 \%)$ & \multirow[t]{2}{*}{$<0.001$} \\
\hline & No, n (\%) & $858(85 \%)$ & $12(48 \%)$ & $73(97.3 \%)$ & \\
\hline \multicolumn{2}{|l|}{ Mean age \pm SD } & $75.9 \pm 7.3$ & $78.1 \pm 7.8$ & $75.1 \pm 7.1$ & 0.073 \\
\hline \multicolumn{2}{|l|}{ Mean $\mathrm{BMI} \pm \mathrm{SD}$} & $27.2 \pm 5.1$ & $26.8 \pm 6.0$ & $27.3 \pm 4.9$ & 0.665 \\
\hline \multirow[t]{2}{*}{ Gender } & Female, n (\%) & $45(45 \%)$ & $13(52 \%)$ & $32(42.7 \%)$ & \multirow[t]{2}{*}{0.417} \\
\hline & Male, n (\%) & $55(55 \%)$ & $12(71 \%)$ & $43(57.3 \%)$ & \\
\hline \multicolumn{2}{|c|}{ Mean number of medications \pm SD } & $6.5 \pm 2.3$ & $5.6 \pm 3.2$ & $6.8 \pm 1.8$ & 0.079 \\
\hline \multicolumn{2}{|l|}{ Mean $\mathrm{CCl}$ score $\pm \mathrm{SD}$} & $5.3 \pm 1.9$ & $6.2 \pm 2.1$ & $5.0 \pm 1.7$ & 0.005 \\
\hline \multicolumn{2}{|c|}{ Median Barthel ADL score (range) } & $65(0-100)$ & $20(0-70)$ & $65(15-100)$ & $<0.001$ \\
\hline \multicolumn{2}{|c|}{ Median Lawton-Brody IADL score (range) } & $7(0-24)$ & $0(0-13)$ & $8(0-24)$ & $<0.001$ \\
\hline \multicolumn{2}{|c|}{ Median MMSE score (range) } & $23.5(0-30)$ & $11(0-30)$ & $25(5-30)$ & $<0.001$ \\
\hline \multirow{2}{*}{$\begin{array}{l}\text { Possible dementia } \\
(A D 8 \geq 2)\end{array}$} & Yes, n (\%) & $66(66 \%)$ & $20(80 \%)$ & $46(61.3 \%)$ & \multirow[t]{2}{*}{0.088} \\
\hline & No, n $(\%)$ & $34(34 \%)$ & $5(20 \%)$ & $29(38.7 \%)$ & \\
\hline \multicolumn{2}{|c|}{ Median AD8 total score (range) } & $4(0-8)$ & $6(0-8)$ & $3(0-8)$ & 0.007 \\
\hline \multirow[t]{4}{*}{ Living with whom } & With spouse, n (\%) & $57(57 \%)$ & $9(36 \%)$ & $48(64 \%)$ & 0.014 \\
\hline & With relatives, $\mathrm{n}(\%)$ & $27(27 \%)$ & $13(52 \%)$ & $14(18.7 \%)$ & 0.001 \\
\hline & Alone, n (\%) & $15(15 \%)$ & $3(12 \%)$ & $12(16 \%)$ & 0.755 \\
\hline & With caregiver, n (\%) & $1(\% 1)$ & $0(0 \%)$ & $1(1.3 \%)$ & 1.000 \\
\hline \multicolumn{2}{|c|}{ Hospitalization due to sepsis and infection, $n(\%)$} & $7(7 \%)$ & $7(28 \%)$ & $0(0 \%)$ & $<0.001$ \\
\hline \multicolumn{2}{|c|}{ Hospitalization due to CAD, n (\%) } & $62(62 \%)$ & $0(0 \%)$ & $62(82.7 \%)$ & $<0.001$ \\
\hline
\end{tabular}


Although it is not statistically significant $(p=0.067)$, there seems to be a higher proportion of patients with AD8 score $\geq 2$ in the delirious group ( $86.7 \%$ vs $62.4 \%$ ). On the other hand, total AD8 score was significantly higher in patients who developed delirium compared to those who had not (Table 2). Furthermore, MMSE score was lower in patients with delirium compared to the ones without delirium (6 vs 22). However, none of our cognitive assessment parameters were significant in multivariate analysis. Nevertheless, many studies in the literature show that dementia is a risk factor for delirium, and patients with delirium have higher rates of cognitive dysfunction and dementia. $(7,24,29,30)$.

Another finding was that living with the spouse was significantly less prevalent in delirious patients whereas living with relatives was significantly more prevalent. Neither of the two factors was significant in multivariate analysis. It has been reported previously that being married is associated with better health and lower mortality (31) but increased delirium severity (32). Our findings suggest that living with the spouse may be protective against delirium. This may be an interesting topic for further research.
Mean number of medications at admission was not different among patients with and without delirium (6.6 vs 6.5) and this factor was not different among patients with and without delirium, when analyzed separately for patients in MICU and CICU (analysis not shown). Nevertheless, it is known that the number of medications and use of particular medications are risk factors for delirium development (24).

\section{Study Limitations}

Our study diverges from other delirium prevalence studies in that it revealed the characteristics of geriatric patients in different ICUs simultaneously. Other strong aspects of our study are evaluation of delirium development not only during admission but also during the whole stay in ICU and interviews performed by a single interviewer in a standardized manner. There are several limitations of this study. First, this is an observational study and the associations can't be interpreted to infer causality. Though the study had a prospective cohort design, the data was recorded to yield prevalent but not incident delirium. In other words, we do not distinguish whether the patient was delirious on admission or it developed later on during their ICU stay. Because the study period covered only 2 months, the sample

\begin{tabular}{|c|c|c|c|c|}
\hline \multicolumn{2}{|l|}{ Variable } & $\begin{array}{c}\text { Delirium } \\
n=15\end{array}$ & $\begin{array}{c}\text { Delirium (-) } \\
n=85\end{array}$ & p value \\
\hline \multicolumn{2}{|l|}{ Mean BMI \pm SD } & $26.2 \pm 6.4$ & $27.3 \pm 4.9$ & 0.441 \\
\hline Gender & Female & $10(66.7 \%)$ & $35(41.2 \%)$ & 0.067 \\
\hline Unit & CICU, n (\%) & $2(13.3 \%)$ & $73(\% 85.9)$ & $<0.001$ \\
\hline \multicolumn{2}{|l|}{ Mean number of medications \pm SD } & $6.6 \pm 2.8$ & $6.5 \pm 2.2$ & 0.842 \\
\hline \multicolumn{2}{|l|}{ Mean $\mathrm{CCl}$ score $\pm \mathrm{SD}$} & $6.7 \pm 2.3$ & $5.0 \pm 1.7$ & 0.001 \\
\hline \multicolumn{2}{|l|}{ Median Barthel ADL score (range) } & $0(0-65)$ & $65(0-100)$ & $<0.001$ \\
\hline Possible dementia (AD8 $\geq 2$ ) & No, n (\%) & $2(13.3 \%)$ & $32(37.6 \%)$ & 0.067 \\
\hline \multicolumn{2}{|l|}{ Median AD8 total score (range) } & $7(0-8)$ & $3(0-8)$ & 0.001 \\
\hline \multirow[t]{4}{*}{ Living with whom } & With spouse, n (\%) & $4(26.7 \%)$ & $53(62.4 \%)$ & 0.010 \\
\hline & With relatives, $\mathrm{n}(\%)$ & $8(53.3 \%)$ & $19(22.4 \%)$ & 0.024 \\
\hline & Alone, n (\%) & $3(20 \%)$ & $12(14.1 \%)$ & 0.694 \\
\hline & With caregiver, n (\%) & $0(0 \%)$ & $1(\% 1.2)$ & 1.000 \\
\hline \multirow[t]{2}{*}{ Hospitalization due to sepsis and infection } & Yes, n (\%) & 6 & 1 & \multirow[t]{2}{*}{$<0.001$} \\
\hline & No, n (\%) & 9 & 84 & \\
\hline Hospitalization due to CAD & Yes, n (\%) & 2 & 60 & $<0.001$ \\
\hline
\end{tabular}




\begin{tabular}{|c|c|c|}
\hline \multicolumn{3}{|c|}{$\begin{array}{l}\text { Table 3. Predictors of Delirium Risk-multivariate Logistic } \\
\text { Regression Analysis }(n=100)\end{array}$} \\
\hline Risk Factor & p value & $\begin{array}{c}\text { OR } \\
\text { (95\% Cl Lower-Upper Limit) }\end{array}$ \\
\hline Age & 0.867 & $0.99(0.86$ \\
\hline Service/Unit & 0.647 & 0.5 \\
\hline Barthel ADL score & $<0.001$ & $0.91(0.86-0.96)$ \\
\hline \multicolumn{3}{|c|}{$\begin{array}{l}\text { ADL: Activities of daily living, } \mathrm{CICU} \text { : Coronary intensive care unit, OR: Odds ratio, } \mathrm{Cl} \text { : } \\
\text { Confidence interval }\end{array}$} \\
\hline
\end{tabular}

size is small. Another limitation is that some assessment tools we used have not been validated in the Turkish population (i.e. Lawton-Brody IADL index) and some have been validated only after our study have been conducted (i.e. AD8) (20).

\section{Conclusion}

Delirium rate is higher in MICU compared to $\mathrm{CICU}$ of a university hospital as expected (52\% vs $2.7 \%$ ). It is also seen that many risk factors associated with delirium are more common in MICU compared to $\mathrm{CICU}$. Although factors such as age, $\mathrm{CCl}$ score, Barthel ADL score, Lawton-Brody IADL score, MMSE score and total AD8 score are different among patients with and without delirium, ADL score is the only independent predictor of delirium. Larger studies will be helpful in determining the risk factors in more detail. Nevertheless, a thorough follow-up of patients especially with restricted ADL in ICUs can be useful in early recognition of delirium which confers a high risk of mortality and morbidity.

\section{Acknowledgement}

We would like to thank Dr. Serdar Yıldırım (Department of Public Health, Süleyman Demirel University Faculty of Medicine) for his assistance in statistical analysis.

\section{Ethics}

Ethics Committee Approval: The study was approved by Süleyman Demirel University Faculty of Medicine Ethics Committee, and informed consent was obtained from the patients or their relatives (decision no: 202).

Informed Consent: Informed consent was obtained from the patients or their relatives.

Peer-review: Externally and internally peer-reviewed.

\section{Authorship Contributions}

Concept: Z.D.A., H.Y., Design: Z.D.A., H.Y., Data Collection or Processing: Z.D.A., H.Y., Analysis or Interpretation: Z.D.A., H.Y., Literature Search: Z.D.A., H.Y., Writing: Z.D.A., H.Y.

Conflict of Interest: No conflict of interest was declared by the authors.
Financial Disclosure: The authors declared that this study received no financial support.

\section{References}

1. O'Mahony R, Murthy L, Akunne A, Young J; Guideline Development Group. Synopsis of the National Institute for Health and Clinical Excellence guideline for prevention of delirium. Ann Intern Med 2011;154:746-751.

2. American Psychiatric Association. Diagnostic and Statistical Manual of Mental Disorders, 5th Edition, American Psychiatric Press, Washington DC 2013, pp 596-602. Available from: http://dsm.psychiatryonline.org/book. aspx?bookid=556. DOI: 10.1176/appi.books.9780890425596.

3. Inouye SK, van Dyck CH, Alessi CA, Balkin S, Siegal AP, Horwitz RI. Clarifying confusion: the confusion assessment method. A new method for detection of delirium. Ann Intern Med 1990;113:941-948.

4. Wong CL, Holroyd-Leduc J, Simel DL, Straus SE. Does this patient have delirium?: value of bedside instruments. JAMA 2010;304:779-786.

5. Wei LA, Fearing MA, Sternberg EJ, Inouye SK. The Confusion Assessment Method: a systematic review of current usage. J Am Geriatr Soc 2008;56:823-830.

6. Inouye SK, Rushing JT, Foreman MD, Palmer RM, Pompei P. Does delirium contribute to poor hospital outcomes? A three-site epidemiologic study. J Gen Intern Med 1998;13:234-242.

7. McNicoll L, Pisani MA, Zhang Y, Ely EW, Siegel MD, Inouye SK. Delirium in the intensive care unit: occurrence and clinical course in older patients. J Am Geriatr Soc 2003;51:591-598.

8. Neufeld KJ, Thomas C. Delirium: definition, epidemiology, and diagnosis. J Clin Neurophysiol 2013;30:438-442.

9. Xie GH, Fang XM. Importance of recognizing and managing delirium in intensive care unit. Chin J Traumatol 2009;12:370-374.

10. Arend $E_{1}$ Christensen M. Delirium in the intensive care unit: a review. Nurs Crit Care 2009;14:145-154.

11. Morandi A, Jackson JC. Delirium in the intensive care unit: a review. Neurol Clin 2011;29:749-763.

12. Akinci SB, Rezaki M, Ozdemir H, Celikcan A, Kanbak M, Yorganci K, Aypar $\mathrm{U}$. Validity and reliability of the Turkish version of confusion assesment method for the intensive care unit (CAM-ICU): A-640. European Journal of Anaesthesiology (EJA) 2005;22:167. (abstract)

13. Charlson M, Szatrowski TP, Peterson J, Gold J. Validation of a combined comorbidity index. J Clin Epidemiol 1994;47:1245-1251.

14. de Groot V, Beckerman H, Lankhorst GJ, Bouter LM. How to measure comorbidity. a critical review of available methods. J Clin Epidemiol 2003;56:221-229.

15. Yıldız A, Yiğit A, Benli AR. The prognostic role of Charlson comorbidity index for critically ill elderly patients. The European Research Journal 2019:1-6.

16. Sulter G, Steen C, De Keyser J. Use of the Barthel index and modified Rankin scale in acute stroke trials. Stroke 1999;30:1538-1541.

17. Küçükdeveci AA, Yavuzer $G$, Tennant $A$, Süldür $N$, Sonel $B$, Arasil $T$. Adaptation of the modified Barthel Index for use in physical medicine and rehabilitation in Turkey. Scand J Rehabil Med 2000;32:87-92.

18. Lawton MP, Brody EM. Assessment of older people: self-maintaining and instrumental activities of daily living. Gerontologist 1969;9:179-186.

19. Galvin JE, Roe CM, Xiong C, Morris JC. Validity and reliability of the AD8 informant interview in dementia. Neurology 2006;67:1942-1948.

20. Usarel C, Dokuzlar O, Aydin AE, Soysal P, Isik AT. The AD8 (Dementia Screening Interview) is a valid and reliable screening scale not only for dementia but also for mild cognitive impairment in the Turkish geriatric outpatients. Int Psychogeriatr 2019;31:223-229. 
21. Folstein MF, Folstein SE, McHugh PR. "Mini-mental state". A practical method for grading the cognitive state of patients for the clinician. J Psychiatr Res 1975;12:189-198.

22. Güngen $C$, Ertan T, Eker E, Yaşar R, Engin F. Standardize mini mental test'in Türk toplumunda hafif demans tanısında geçerlik ve güvenilirliği. Türk Psikiyatri Derg 2002;13:273-281.

23. Babacan-Yıldız G, Ur-Özçelik E, Kolukısa M, Işık AT, Gürsoy E, Kocaman G, Çelebi A. [Validity and Reliability Studies of Modified Mini Mental State Examination (MMSE-E) For Turkish Illiterate Patients With Diagnosis of Alzheimer Disease]. Turk Psikiyatri Derg 2016;27:41-6.

24. Limpawattana $P$, Panitchote $A$, Tangvoraphonkchai $K$, Suebsoh N, Eamma W, Chant-honglarng B, Tiamkao S. Delirium in critical care: a study of incidence, prevalence, and associated factors in the tertiary care hospital of older Thai adults. Aging Ment Health 2016;20:74-80.

25. Pauley E, Lishmanov A, Schumann S, Gala GJ, van Diepen S, Katz JN. Delirium is a robust predictor of morbidity and mortality among critically ill patients treated in the cardiac intensive care unit. Am Heart J 2015;170:7986, 86.e1.

26. Colkesen Y, Giray S, Ozenli Y, Sezgin N, Coskun I. Relation of serum cortisol to delirium occurring after acute coronary syndromes. Am J Emerg Med 2013;31:161-165.
27. Hasan A, Gaur R.K, Khan W. A study of delirium in acute coronary syndrome. Indian Journal of behavioural Sciences 2005;17:24-27.

28. Ibrahim K, McCarthy CP, McCarthy KJ, Brown CH, Needham DM, Januzzi JL Jr, McEvoy JW. Delirium in the Cardiac Intensive Care Unit. J Am Heart Assoc 2018;7:e008568.

29. Erden Aki O, Derle E, Karagol A, Turkyilmaz C, Taskintuna N. The prevalence and recognition rate of delirium in hospitalized elderly patients in Turkey. Int J Psychiatry Clin Pract 2014;18:52-57.

30. Naksuk N, Thongprayoon C, Park JY, Sharma S, Gaba P, Rosenbaum AN Peeraphatdit T, Hu TY, Bell MR, Herasevich V, Brady PA, Kapa S, Asirvatham SJ. Editor's Choice-Clinical impact of delirium and antipsychotic therapy: 10-Year experience from a referral coronary care unit. Eur Heart J Acute Cardiovasc Care 2017;6:560-568.

31. Robards J, Evandrou M, Falkingham J, Vlachantoni A. Marital status, health and mortality. Maturitas 2012;73:295-299.

32. Voyer $\mathrm{P}$, Richard $\mathrm{S}$, Doucet $\mathrm{L}$, Carmichael PH. Factors associated with delirium severity among older persons with dementia. J Neurosci Nurs 2011;43:62-69. 